\title{
PROCESSOS REFERENCIAIS E ARGUMENTAÇÃO EMOCIONADA: DO PATHOS À CONSTRUÇÃO DO PONTO DE VISTA
}

\author{
REFERENCIAL PROCESSES AND EMOTIONAL ARGUMENTATION: \\ FROM PATHOS TO THE BUILDING OF POINT OF VIEW
}

Suzana Leite Cortez ${ }^{1}$

\begin{abstract}
RESUMO: A linguística textual brasileira vem há cerca de duas décadas discutindo as diversas funções da referenciação. Dentre as funções, destaca-se a argumentatividade, que se realiza não apenas nos gêneros nos quais o tipo dissertativo predomina, mas em todo e qualquer discurso, no qual o produtor do texto tenta de alguma forma interferir sobre os julgamentos, valores e opiniões de seu interlocutor. Mobilizando as noções de pathos e de ponto de vista, este trabalho analisa o papel da referenciação na "argumentação emocionada" (PINTO; CORTEZ, 2017). Pretende-se, assim, discutir o "lugar do sensível na argumentação" (MICHELI; HEKMAT; RABATEL, 2013), analisando especialmente os processos referenciais.
\end{abstract}

PALAVRAS-CHAVES: processos referenciais, emoção, pathos, ponto de vista.

ABSTRACT: Brazilian Textual Linguistics has been discussing the various functions of referentiation for nearly two decades. Among those functions, argumentation stands out, occurring not only in the genres in which the essay predominates, but in each and every discourse in which the speaker somehow tries to induce the judgments, values and opinions of his interlocutor. By mobilizing the notions of pathos and point of view, this paper brings an analysis of the role of referentiation for "emotional argumentation" (PINTO; CORTEZ, 2017). Therefore, we intended to discuss the "place of sensible in argumentation" (MICHELI; HEKMAT; RABATEL, 2013), by analyzing especially those referential processes.

$\boldsymbol{K E} \boldsymbol{Y}-\boldsymbol{W O R D S}$ : referencial processes, emotion, pathos, point of view.

\section{Introdução}

O estudo de um fenômeno tão complexo como a referenciação integra a agenda da linguística textual no Brasil há cerca de duas décadas², lançando reflexões sobre o texto, sua organização, produção, compreensão, das quais são inescapáveis a construção da coerência, os processos referenciais, as relações anafóricas, a intertextualidade, a (inter)subjetividade,

\footnotetext{
${ }^{1}$ Professora do Departamento de Letras e do Programa de Pós Graduação em Letras da UFPE.

${ }^{2}$ Considero aqui a publicação de dois textos, de Ingedore Villaça Koch e Luiz Antônio Marcuschi, escritos em parceria: "Estratégias de referenciação e progressão referencial na língua falada" e "Processos de referenciação na produção discursiva" publicados respectivamente na Gramática do Português Falado, v.8 (1997) e Revista DELTA, 14, n. especial (1998).
} 
etc. Destacando nuances ${ }^{3}$ da (re)construção dos objetos de discurso, em diferentes gêneros textuais, a linguística textual (LT) de vertente sociocognitiva e interacional, tem mostrado a atualidade do tema ${ }^{4}$ que também "pode interessar a diversas áreas de conhecimento", pois, como explica Cavalcante (2015), a "referenciação é um dos critérios mais indispensáveis para a elaboração e interpretação da coerência, e a coerência é a condição fundamental do texto." (p.375).

Tal entendimento, possível graças à renovação teórica no estudo da referência, é uma prova de que seu estudo, ao estender-se sobre a dimensão do texto-discurso, resultou num olhar já bem consolidado, no campo da LT, sobre as operações de designação, identificação e interpretação referencial, superando a "noção meramente referencialista e representacionalista da língua, para privilegiar as relações intersubjetivas instauradas pelos interlocutores ${ }^{5}$ mediante recursos linguísticos" (MARCUSCHI, 2004, p. 273). Do mesmo modo, não é possível tratar os referentes unicamente como elementos de coesão, utilizados para evitar a repetição em textos, preferencialmente escritos. Ao contrário, por meio desta renovação teórica, colocam-se em evidência funções diversas das estratégias e dos elementos de referenciação:

a referenciação não se presta, pois, somente a não repetir formas de expressão referencial em um contexto, mas a organizar o texto, a argumentar, a resumir, a introduzir novas informações, a definir, a veicular diferentes vozes ou pontos de vista discursivos, a chamar a atenção do leitor - para citar apenas algumas.(CAVALCANTE, 2011, p. 186)

Corroborando com tal afirmação, Cavalcante, Custódio Filho e Brito (2014) postula que os processos referenciais, de introdução referencial, dêixis e anáfora, "atendem a funções várias, que tem como finalidade última colaborar para a construção da coerência/coesão textual e discursiva" (p.53). Em outras palavras, pode-se dizer que, numa dimensão sociocognitivo-interacional-discursiva, os estudos de referenciação discutem essas outras funções dos processos referenciais ${ }^{6}$, os quais vêm sendo atentamente estudados no campo da LT. Dentre as funções dos processos referenciais, destaco a argumentatividade.

\footnotetext{
${ }^{3}$ Dentre estas nuances, citam-se: a introdução referencial, a recategorização anafórica, o encadeamento dos referentes, a seleção lexical para a construção das expressões referenciais, em textos mais diversos, orais e escritos, inescapáveis a algum tipo de modalidade (imagética, gráfica, sonora, gestual) ou modalidades.

${ }^{4}$ Cf. Cavalcante (2015). Nesta entrevista concedida à Revista Revel, v.13, n.25 dedicado exclusivamente à referenciação, a autora descreve o estado da arte das pesquisas sobre este tema no Brasil.

${ }^{5}$ Ênfase adicionada.

${ }^{6}$ Destaco aqui as diversas publicações, além de dissertações e teses desenvolvidas no âmbito do PROTEXTO, grupo de pesquisa coordenado pela Profa. Mônica Magalhães Cavalcante. Embora sediado na UFC, o grupo compõe-se de pesquisadores de diversas universidades no Brasil.
} 
No quadro da LT, a argumentação também vem sendo estudada em diálogo ${ }^{7}$ com diferentes perspectivas. Cavalcante (2016) assinala quatro "maneiras de lidar com as questões da argumentação na tradição dos estudos" (p.106) da LT no Brasil: i) trabalhos orientados pela Teoria dos Blocos Semânticos, ii) estudos que seguem a Análise Textual dos Discursos, com base em Jean-Michel Adam, iii) trabalhos que adotam os critérios da Semiolinguística de Charaudeau e iv) estudos que se fundam em postulados da Retórica e da Nova Retórica. Mais recentemente, a autora tem se voltado ao estudo discursivo de aspectos da argumentação em convergência com a perspectiva de Amossy (2006), para quem a linguagem "comporta sempre uma dimensão argumentativa" (p.33), mesmo quando não há um projeto declarado ou estratégias explícitas.

Esse entendimento do que é explícita ou implicitamente argumentativo, é tratado por Rabatel (2017, p.27), respectivamente como argumentação direta e argumentação indireta. A direta realiza-se por meio de argumentos, conectores, enquanto que a indireta dá-se por meio de "inferências a partir da construção dos objetos de discurso", em que se argumenta sem que se pareça argumentativo. $\mathrm{O}$ autor sintetiza o que sustenta seu entendimento da argumentação:

\begin{abstract}
Ao retomar a dicotomia esboçada por Amossy (2006), baseio-me em uma concepção de argumentação que provém mais da dimensão argumentativa (argumentação indireta) do que da visada argumentativa (argumentação direta, explicitamente organizada), privilegiando mais a lógica inferencial de Grize (2002) do que a lógica silogística. (RABATEL, 2016, p.132) ${ }^{8}$
\end{abstract}

Rabatel (2017) esclarece que a argumentação indireta é bastante produtiva e recorrente nos textos literários, desempenhando também um papel fundamental nos textos midiáticos, especialmente aqueles que têm a pretensão de objetividade ocultando-se por uma espécie de visada informativa. Tal entendimento é o ponto de partida para reconhecer a argumentatividade não apenas nos gêneros tidos como argumentativos, nos quais o tipo dissertativo predomina, mas, em todo e qualquer discurso, no qual o produtor do texto tenta de alguma forma interferir sobre os julgamentos, opiniões e preferências de seu interlocutor. Considerando que essa interferência é comumente marcada pelo apelo ao sensível, quer dizer, por modos de dar visibilidade às emoções, o que envolve necessariamente a expressão de valores e sentimentos, analiso neste trabalho o papel dos processos referenciais na

\footnotetext{
${ }^{7}$ A relação entre esses distintos objetos, no campo da linguística textual, dá-se pela sua propensão interdisciplinar, com base na forma como concebe o texto, considerando-o como "o próprio lugar da interação", em que os interlocutores, como sujeitos ativos, "nele se constroem e são construídos" (KOCH, 2002, p. 17).

8 Todos os trechos das obras acadêmicas em língua francesa são traduções deste artigo.
} 
"argumentação emocionada" (PINTO; CORTEZ, 2017) ${ }^{9}$. Apesar de a análise ter como foco as emoções, será preciso situá-las em relação ao pathos, dado o valor que essa noção adquiriu nos estudos retórico-argumentativos - da tradição aristotélica aos estudos contemporâneos da argumentação (cf. PLANTIN, 2005; AMOSSY, 2006). Assim, discutirei, ainda que de forma provisória, como o pathos constitui a argumentação e se relaciona às emoções ${ }^{10}$ para, em seguida, analisá-las como estratégias articuladas à construção do ponto de vista. Antes disso, apresento a axiologia dos processos referenciais.

\section{Axiologia dos processos referenciais}

Enquadrando o estudo da referência numa perspectiva sociocognitiva, Marcuschi (2002, p.69) postula que "os processos de referenciação ocupam um lugar central na construção do mundo de nossas vivências" ${ }^{\prime 1}$. Por essa ótica, o mundo comunicado é sempre fruto de um agir intersubjetivo, que decorre da nossa inserção sociocognitiva no mundo em que vivemos. Essa dinamicidade afeta o processamento da referência, isto é, a referenciação dos objetos de discurso, resultante não de uma ontologia dada, mas de práticas simbólicas complexas. Essas práticas, segundo Mondada e Dubois (1995), estão associadas à construção de objetos cognitivos e discursivos na intersubjetividade de negociações e modificações de concepções públicas do mundo ${ }^{12}$.

Essa visão construtiva da referência possibilita um olhar dinâmico para os "processos referenciais", de introdução referencial, dêixis e anáfora, tal como compreendidos por Cavalcante, Custódio Filho e Brito (2014). No quadro da referenciação, estes três processos, conjugados no texto, são constitutivos da progressão referencial, o que leva a situá-los não apenas como aspectos importantes para a continuidade tópica e coesão textual, mas principalmente para a construção da coerência. Nesse sentido, a interpretação referencial torna-se crucial para a identificação e análise dos referentes, que não se faz apenas por

\footnotetext{
${ }^{9}$ Nesta entrosada parceria com Rosalice Pinto, pesquisadora do Centro de Linguística da Universidade Nova de Lisboa, analisamos a materialização linguística do que denominamos argumentação emocionada em texto midiático de natureza polêmica. Por meio dessa análise, estreitamente apoiada nos trabalhos de Alain Rabatel, entendemos como fundamental no estudo da noção de pathos: a importância das "representações" que se tem da emoção do outro (dimensão empática das emoções) para a construção argumentativa de textos/discursos.

${ }^{10}$ Agradeço a Mônica Magalhães Cavalcante, a quem devo este entendimento.

11 A discursivização/textualização do mundo pela linguagem é tão complexa que, como assinalaram Koch e Marcuschi (1998), não implica um simples processo de representação da realidade física ou mental, mas uma "(re)construção" do próprio real pela reelaboração de conhecimentos e organização da experiência.

${ }^{12}$ Por isso, as verdades constituem "produções discursivas", que têm como ponto de intersecção o mundo empírico e mentes que podem agir intersubjetivamente. Isso faz com que a própria objetividade tenha sua fonte na intersubjetividade, já que o conhecimento dito objetivo, assim como as verdades e categorizações, são frutos de uma "triangulação entre dois indivíduos e o mundo" (MARCUSCHI, 2007, p.132). Assim, os objetos de conhecimento são objetos de discurso.
} 
intermédio da expressão referencial ou do(s) elemento(s) linguístico(s) que pontualmente identifica(m) a introdução referencial, a dêixis e a anáfora. Daí estes serem considerados processos, e não apenas categorias operadas linguisticamente, tampouco restritas de maneira pontual ao termo ou à expressão que os materializa. Essa visão dinâmica possibilita considerar as conexões que envolvem o processamento do referente em textos, isto é, os aspectos de ordem linguística, cognitiva, racional, emotiva, social, cultural, pragmática, ideológica que se entrelaçam na construção dos referentes. Para Cavalcante, Custódio Filho e Brito (2014, p.155), "qualquer pista verbal ou não verbal pode levar o interlocutor a construir referentes no texto".

Essa abordagem processual evidencia maior compreensão da riqueza do fenômeno da referenciação. Para Marcuschi (2005), a noção ampliada da anáfora, não restrita à coreferenciação, implica necessariamente considerar, que os processos cognitivos e estratégias inferenciais são decisivos na atividade de textualização, o que acaba por afetar o entendimento de como se instaura a coerência no texto. Para Custódio Filho ${ }^{13}$ (2012, p.844), "Essa categoria não pode mais ser entendida nos limitados moldes da relação de identificação entre sintagmas presentes num texto. Ela é, na verdade, a unidade poderosa [...], passível de retomar elementos os mais diversos e de realizar múltiplas funções." ${ }^{14}$.

Por essa forma de compreender a construção dos referentes, o léxico é visto como um material constantemente (re)trabalhado no discurso. Apothéloz e Reichler-Béguelin (1995) entendem que o emprego do léxico para a referência está submetido a um conjunto de dispositivos extremamente maleáveis e contextualmente trabalhados no e pelo discurso, que não pode ser feito independentemente da instância que a toma sob sua responsabilidade. Por isso, como esclarece Mondada e Dubois (1995), a instabilidade dos objetos de discurso, possível pela recategorização, depende muito mais da multiplicidade de pontos de vista que os sujeitos exercem sobre o mundo, do que de um contrato imposto pela sua materialidade. Aquilo que é dito estável sobre um objeto pode ser descategorizado, recategorizado sob efeito de uma mudança de contexto ou de ponto de vista.

Ao se referirem à função avaliativa da recategorização na formulação de um juízo de valor, Ciula e Matos (2016, p.262) assinalam que esta "é a função desempenhada por processos recategorizadores que mais se destaca na construção da argumentação, já que a atribuição de valor axiológico relaciona-se de maneira muito estreita à condução

\footnotetext{
${ }^{13}$ Para este autor, a referenciação é uma proposta teórica que fortalece o "poder" da anáfora.

${ }^{14}$ Esses elementos, portanto, dizem respeito não apenas ao que é expresso verbalmente no texto, mas também a referentes expressos visualmente e a elementos presentes na memória discursiva que podem ser resgatados a partir de pistas contextuais.
} 
argumentativa dos enunciados." Sendo assim, podemos dizer, em consonância com as autoras, que o dinamismo semântico do léxico contribui para que os referentes possam impregnar-se de valores distintos, mesmo antagônicos, a depender das emoções mobilizadas pelos enunciadores. As autoras postulam ainda que "certos nomes parecem apresentar a tendência, maior ou menor, de serem usados de maneira valorativa, auxiliando no processo de construção da argumentação." (p.265). Sobre isto, acrescentamos que quando as expressões referenciais são usadas axiologicamente, independentemente do grau, elas contribuirão para mobilizar emoções. Em outras palavras, o caráter axiológico dos processos referenciais está diretamente ligado ao apelo às emoções, em menor ou maior grau, uma vez que mobiliza valores. Assim, os referentes, quando portam valores, seja (explicitamente) através da expressão referencial, seja (difusamente) através de inferências ou de conexões estabelecidas a partir da tessitura textual, são indícios de emoção. Nesse caso, parece que independente do grau, se mais ou menos emotivo, há valoração, portanto argumentação emocionada.

\section{Argumentação emocionada: do pathos ao ponto de vista}

"As emoções, como se sabe, figuraram longo tempo como 'parentes pobres' das teorias da argumentação - esta em contraste flagrante com a riqueza da reflexão retórica sobre o pathos." (MICHELI; HEKMAT; RABATEL, 2013, p.11). Nas últimas duas décadas, contudo, esse lugar coadjuvante em que as emoções foram postas vem se modificando. Embora seja complexo ${ }^{15}$ encontrar um espaço "conciliador" ao par emoção e pathos na argumentação, pode-se dizer, mesmo preliminarmente, que o pathos não prescinde das emoções. Para Amossy (2006, p.187), o pathos é o "efeito emocional produzido sobre o alocutário". Dessa forma, o pathos, enquanto sentimento suscitado no auditório, não se confunde com a emoção evocada no texto, isto é, com o sentimento que o sujeito falante sente e exprime. Assim, o pathos estaria mais no nível da provocação (na esfera do destinatário, público, leitor), enquanto que as emoções estariam no nível da evocação (emanada do falante, locutor/enunciador, produtor do texto).

\footnotetext{
${ }^{15}$ Isso decorre não apenas da dívida histórica dos estudos da argumentação com o campo da retórica, mas também da dívida da própria linguística em tardar a estudar a argumentação de forma contextualmente situada em variados textos/discursos. Essa abertura convoca ao diálogo da linguística (incluo a textual) com diferentes noções (subjetividade, intencionalidade, inferência, empatia, emoções, afetos, logos, pathos, ethos, intertextualidade, ideologia, ponto de vista, etc.) e áreas (dentro e fora da linguística - linguística textual, análise de discurso, retórica, lógica, filosofia, cognição, psicologia, antropologia, estudos culturais, etc.).
} 
Evidentemente, essa distinção não exclui a interligação desses fenômenos (produção e recepção) ${ }^{16}$ sobretudo quando a análise tem por base uma abordagem sociointeracionista da língua e do processamento sociocognitivo do texto, para a qual a coerência é co-construída. Ademais, a própria evocação da emoção pode ser vista como estratégia inseparável da provocação. No entanto, uma investigação integradora emoção-pathos demandaria trabalho de maior proporção, que contemplasse, por exemplo, uma análise das reações do leitor/ouvinte ao texto. Por isso, a análise será aqui limitada à emoção expressa pelo locutor no texto, integrando-se aos trabalhos que se dedicam a analisar "o lugar do sensível na argumentação" (MICHELI; HEKMAT; RABATEL, 2013) para a construção do ponto de vista (RABATEL, 2016, 2017).

Como assinala Micheli, Hekmat e Rabatel (2013), os trabalhos de Christian Plantin ${ }^{17}$ trazem grande contribuição para essa redefinição do lugar das emoções na argumentação. Esses autores mostram que, por essa visão, as emoções não são apenas recursos mobilizados para aumentar a eficácia de um raciocínio, mas são também objetos da argumentação, no sentido de que se pode analisar (julgar/criticar) emoções utilizando raciocínios em seu (des)favor. Para Amossy (2006), a emoção resultante de uma argumentação pode, "após ter sido explicitamente mencionada, ser sustentada e justificada pela razão" (p.190). É o que pode ser observado, por exemplo, no trecho do depoimento emocionado de Robson Rodrigues, coronel da PM do Rio de Janeiro, publicado no facebook em favor da vereadora Marielle Franco:

Cada morte violenta me arranca um pedaço da alma, pois os 60 mil homicídios ao ano nos distancia, e muito, do lugar civilizatório que, julgo, mereceríamos ocupar como o país lindo como o nosso. Calo, sofro, choro em silêncio. Não me apraz falar, não me apraz comparecer a rituais de despedida fúnebre e sentir o sofrimento das pessoas, principalmente dos familiares, em respeito a suas dores. O cargo me obrigou a assistir inúmeros enterros, de inúmeras vítimas policiais de uma guerra fratricida que nos prostra enquanto seres humanos. Uma guerra inglória. Abri uma exceção por um dever de consciência; para falar de uma amiga, a vereadora Marielle, porque, se sua morte me impactou, muito mais tem impactado a forma vil e cega e infame como ela vem sendo tratada por algumas pessoas nas redes sociais. Pessoas que não conheceram Marielle. Senti-me na obrigação de informar a amigos

\footnotetext{
${ }^{16}$ Forget (2016) insiste sobre a necessidade de a emoção não ser abordada exclusivamente do ponto de vista de sua expressão, alcançando o terreno do phatos. A autora defenda que pathos e interação estão intimamente relacionados, analisando em crônicas o que chama de "dispositivo persuasivo baseado no pathos". Forget pontua o papel das análises semânticas e pragmáticas para observar os mecanismos de interpretação e recepção das emoções, quer dizer, a "carga patética" em contexto argumentativo estreitamente ligada à persuasão.

${ }^{17}$ Sem polarizar ethos e pathos, Plantin (2008) considera que ambos se recobrem: "a correta consideração das dimensões do ethos e do pathos implica o desenvolvimento de uma teoria dos afetos no discurso." (p.111)
} 
desinformados sobre quem ela era; amigos que considero e que são bombardeados por bobagens e falsas informações sobre a vereadora que não conheceram. ${ }^{18}$

https://www.facebook.com/permalink.php?story_fbid=776307825901140\&id=100005657881748

No trecho, o locutor fala explicitamente do que sente, argumentando por meio de emoções: "cada morte violenta me arranca um pedaço da alma", " Calo, sofro, choro em silêncio.", " se sua morte me impactou, muito mais tem impactado a forma vil e cega e infame como ela vem sendo tratada por algumas pessoas nas redes sociais". O autor conjuga essas emoções utilizando raciocínios em seu favor, tais como: " pois os 60 mil homicídios ao ano nos distancia, e muito, do lugar civilizatório que, julgo, mereceríamos ocupar", " O cargo me obrigou a assistir inúmeros enterros, de inúmeras vítimas policiais de uma guerra fratricida que nos prostra enquanto seres humanos."

Assim, pode-se argumentar por emoções, o que possibilita observar como estas são usadas para argumentar ${ }^{19}$. Consoante a Amossy (2006), uma análise das emoções no discurso permite considerá-las como explicitamente mencionadas, quando se aponta para uma emoção, ou apenas provocadas, ainda que não designadas por "termos de sentimento". De forma semelhante, Micheli, Hekmat e Rabatel (2013) postula que na "construção argumentativa das emoções em discurso", o locutor argumenta por meio das emoções ou sobre as emoções. Por meio das emoções, é o que será observado nas duas amostras apresentadas mais abaixo: duas telas de Nicolas Régnier e respectivas plaquetas descritivas, que analisam a obra. Os processos referenciais em ambas levam a crer que as emoções, como estratégias discursivas, atuam diretamente na construção de pontos de vista. Conforme defende Plantin (2008, p.124), "é impossível construir um ponto de vista, um interesse, sem a eles associar um afeto", consequentemente as situações argumentativas não prescindem da presença de um elemento irredutivelmente emocional. Dessa forma, a noção de o ponto de vista (PDV), torna-se crucial na análise da argumentação emocionada.

De forma genérica, o ponto de vista, pode ser linguisticamente definido, segundo Rabatel (2008), pelos meios linguísticos através dos quais, o sujeito, singular ou coletivo, considera um objeto de discurso (personagem, situação, noção, evento, objeto concreto, etc). O sujeito, responsável pela referenciação do objeto, "exprime seu PDV tanto diretamente, por comentários explícitos, tanto indiretamente pela referenciação, quer dizer, pelas escolhas de seleção, atualização e combinação do material linguístico." (p.21). Todavia, para Rabatel, o

\footnotetext{
${ }^{18}$ Acesso em 21/03/208. Texto publicado em 17 de março de 2018.

${ }^{19}$ Micheli, Hekmat e Rabatel (2013) falam em "observabilidade das emoções".
} 
$\mathrm{PDV}^{20}$ não se limita a um conceito linguístico, sendo antes de tudo "uma postura cognitiva e psicossocial". Na concepção deste autor, o PDV é "todo saber (e possivelmente as opiniões ou julgamentos de valor aí associados) na base de um conteúdo proposicional" (p. 263) - o dito e o dizer remetendo à instância enunciativa que o assume, mesmo sem esta seja mencionada de forma explícita. Uma questão crucial é que o PDV se constrói necessariamente em contexto dialogal: "os pontos de vista nunca emergem ex nihilo, mas se constroem na interação" (p.263), seja quando o locutor se posiciona em relação a outros PDVs já considerados, seja quando o locutor se direciona ao interlocutor cujos PDVs antecipa.

Esse dupla direção do PDV permite considerar, como faz Rabatel (2017, p.310), que as emoções na argumentação são não apenas ditas ou inferidas, mas também representadas. É por essa compreensão que o autor trata do caráter empático ${ }^{21}$ das emoções, pois é pelo viés da emoção - tomada "como categoria englobante que abarca noções conexas como humor, afetos, valores e sentimentos" (RABATEL, 2013, p.65) - que o enunciador se coloca no lugar do outro, interpretando-o, para construir pontos de vista em consonância ou dissonância. Por esse "regime empático", as falas, percepções e ações, que no discurso expressam PDVs, possibilitam inferir emoções, porque são um modo de representá-las.

Os modos de semiotização das emoções são extremamente diversos e heterogêneos, conjugando elementos verbais, não verbais, além dos conhecimentos que estes ativam e convocam. Focalizando a axiologia dos processos referenciais na argumentação emocionada no par tela e plaqueta descritiva (figuras 1 e 2 mais abaixo), é possível analisar o ponto de vista a partir do qual se constrói o referente principal "a morte de Sofonisba ${ }^{22 ", ~ q u e ~ d a ́ ~ t i ́ t u l o ~ a ̀ ~}$ tela de Nicolas Régnier. Embora a tela expresse apenas o momento que antecede a morte da princesa, ela projeta o referente a partir das emoções representadas no quadro. Essa projeção imagética arquiteta a comoção, por um tipo de introdução referencial que, de forma empática às personagens, faz ver o motivo trágico de sua morte: tomar uma taça de veneno a pedido do amado, Massinissa, para não sofrer a humilhação de ser capturada por Syphax, adversário de seu noivo. Sofonisba, no centro da tela, é destacada com expressiva sensualidade e dor pela iluminação de sua face, colo e pescoço. Tem sua cabeça inclinada a algo que parece acima de sua condição e sentimento, o qual evoca para render-se ou compreender (a)o pedido do

\footnotetext{
${ }^{20}$ Rabatel (2008, p.57) esclarece que a diferença entre "ponto de vista" e os parassinônimos "atitude" e "posição" reside no fato de que a construção do PDV não é necessariamente tributária das "falas referidas a um locutor por meio do discurso direto ou julgamento explícito implicando a presença do $e u^{\prime \prime}$.

${ }^{21}$ Questão analisada por Pinto e Cortez (2017) na argumentação de ordem polêmica.

${ }^{22} \mathrm{O}$ fato situa-se no contexto das guerras púnicas, que no século III a.C, na cidade de Cartago, opõem a Numídia oriental à ocidental. A morte da princesa, filha de um general cartaginense, é contada por historiadores como Tito Lívio e Plutarco. Sofonisba, famosa por sua beleza e instrução, é alvo de disputa de dois inimigos numídios.
} 
amado. A carta em suas mãos é o desencadeador do drama, porque anuncia a ordenação de Massinissa. Outros elementos ancoram a construção do referente "morte" nesta tríade feminina, integrando a rede referencial do quadro. Além de Sofonisba, como objeto de discurso, vê-se a criada que olha com tristeza para o público, evocando piedade, e à direita, sua confidente que, comovida e de cabeça inclinada para baixo, usa de um grande lenço para enxugar suas lágrimas:

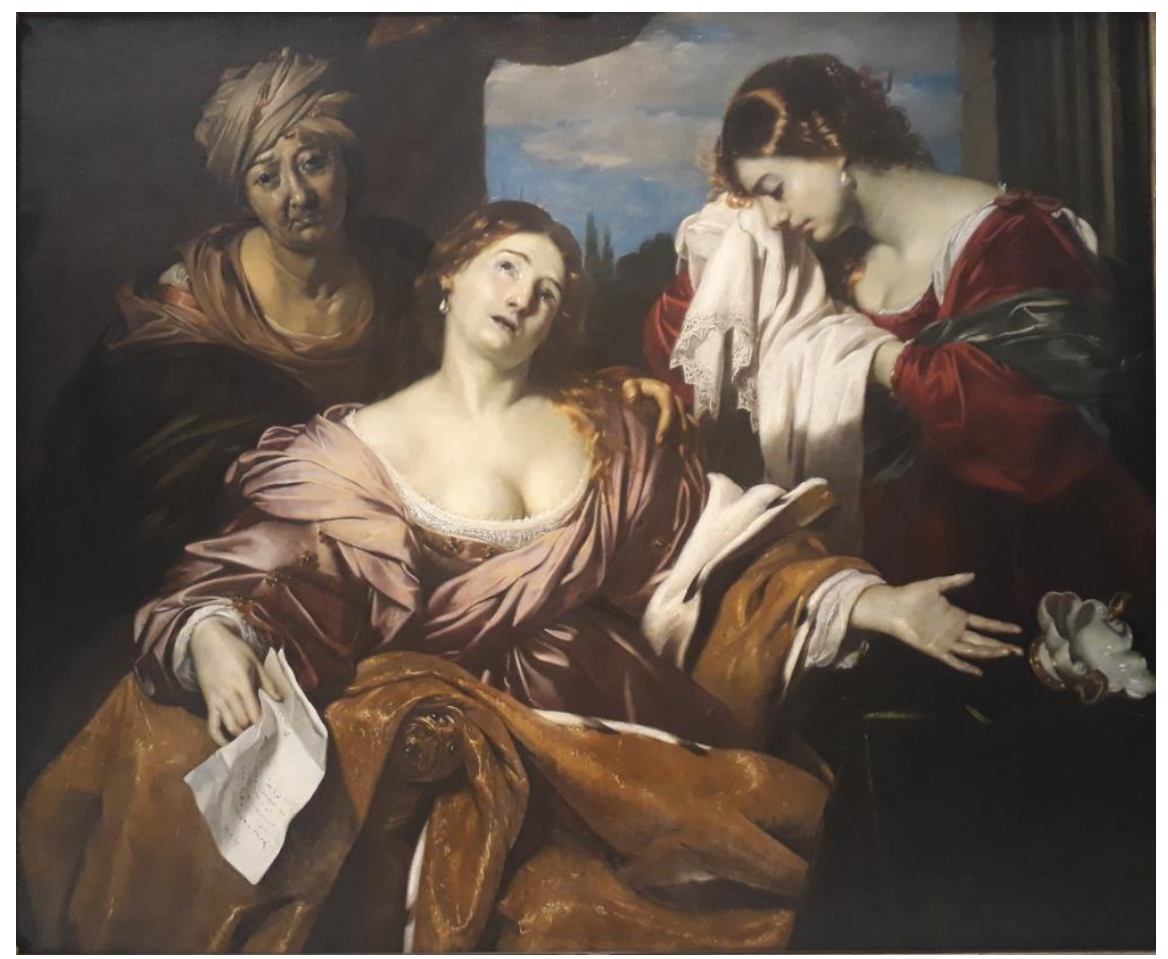

Figura 1: Tela de Nicolas Régnier ${ }^{23}$. A morte de Sofonisba. 1640-1650. Museumslandschaft Hessen Kassel

O texto verbal, na figura 2, que descreve a tela acima apresenta expressões referenciais que ancoram duplamente o referente, como tela exposta no museu e como acontecimento histórico. Ao demais, os mesmos referentes femininos da tela reaparecem na plaqueta. Embora a plaqueta seja em geral considerada como um texto meramente descritivo, importa analisar como nela se expressa a argumentação emocionada. Ainda que os termos utilizados não sejam necessariamente "de sentimento" (Cf. AMOSSY, 2006), nem assinalem a emoção das personagens, eles constroem uma argumentação emocionada. Para tanto, mobilizam o sensível que, ancorado no texto pela axiologia dos processos referenciais e dos argumentos progressivamente utilizados, evidenciam um ponto de vista favorável à comoção da princesa,

\footnotetext{
${ }^{23}$ Fotografei a tela na exposição L'Homme Libre, realizada no Musée d'Arts de Nantes, na França, em dezembro de 2017. Essa exposição foi a primeira inteiramente dedicada ao pintor italiano, recentemente descoberto.
} 
ainda que o texto nada afirme sobre suas emoções. O enunciador parece lamentar a morte deliberada da princesa cujo destino está nas mãos de dois inimigos:

Sophonisbe appartient à une lignée de belles captives au destin tragique, comme Cléopâtre. Lors des guerres puniques au $3^{\text {e }}$ siècle avant Jésus-Christ, Sophonisbe, princesse carthaginoise, est mariée par son père à Syphax. Mais elle était auparavant amoureuse et promise à un autre chef numide, Massinissa, passé par dépit dans le camp romain. Ce dernier écrase les armées numides et épouse alors sa belle captive. Le général romain Scipion lui ordonne de livrer Sophonisbe. L'amant meurtri fait porter une coupe empoisonnée à son épouse pour respecter sa promesse de ne jamais la livrer aux Romains. Régnier oppose le visage ridé de la domestique à la sensualité de Sophonisbe, alanguie dans lécrin bouillonnant de ses atours, et à la perfection du jeune profil éploré d'Herminie, sa confidente.

Figura 2: Plaqueta ${ }^{24}$ referente à tela "A morte de Sofonisba"

A plaqueta mobiliza o sensível logo de início ao jogar com os termos bela e destino trágico na primeira retomada anafórica da personagem por hiperonímia ("belas condenadas ao destino trágico"), conferindo-lhe atributos por seu infortúnio. Esse ponto de vista é reforçado pelo comparativo "como Cleópatra", que aciona outros conhecimentos. Dessa forma, é justamente sua condição de "princesa cartaginense" (mais um atributo) que a leva à morte, realçando na argumentação seu destino trágico. Ademais, o contexto das guerras púnicas, a introdução do referente "uma taça envenenada" e anáfora "sua bela condenada" abrem espaço para a expectativa e concretização da tragédia. Outros elementos, ainda que não sejam identificados como processos referenciais contribuem para construir os referentes "a morte de Sofonisba" e a própria Sofonisba, além de fazer progredir os argumentos no texto, mobilizando emoções. Por exemplo:

i) o atributo ser "casada por seu pai com Syphax" expõe a passividade da personagem cuja vida é conduzida por decisões de poder, assim como a proposição: "O general Scipion ordena-lhe que entregue Sofonisba" (a bela, portanto, é refém);

\footnotetext{
${ }^{24}$ Texto da plaqueta da exposição L'Homme Libre, do Musée d'Arts de Nantes (França), referente à tela "A morte de Sofonisba" (figura 1). Tradução do trecho neste artigo: "Sofonisba pertence a uma linha de belas condenadas ao destino trágico, como Cleópatra. Na época das guerras púnicas do $3^{\circ}$ século antes de Cristo, Sofonisba, princesa cartaginense, é casada por seu pai com Syphax. Mas no passado, foi apaixonada e prometida a outro chefe numídio, Massinissa, que passou por humilhação no campo romano. Esse último esmaga os exércitos numídios e casa-se com sua bela condenada. O general romano Scipion ordena-lhe que entregue Sofonisba. O amante ferido faz chegar a sua esposa uma taça envenenada para respeitar sua promessa de jamais se entregar aos Romanos. Régnier opõe o rosto enrugado da criada à sensualidade de Sofonisba, lânguida na tela impregnada de sua elegância, e à perfeição do jovem perfil em luto de Hermínia, sua confidente."
} 
ii) o tom de passividade, contudo, não apaga a paixão e expectativa que habitam o espírito da personagem, o que é reforçado pelo emprego do "mas": "Mas no passado, foi apaixonada e prometida a outro chefe numídio";

iii) o tom emotivo é ainda reforçado por atributos de Massinissa, que contribuem para inscrever empaticamente o PDV desse personagem : "Massinissa, que passou por humilhação no campo romano" (é vítima, pois foi humilhado) e "Esse último esmaga os exércitos numídios e casa-se com sua bela condenada" (portanto, é valente e luta para conquistar a amada).

Outros referentes da tela, são (re)construídos no texto da plaqueta, como atestam as introduções referencias por expressões meronímicas: "o rosto enrugado da criada", "a sensualidade de Sofonisba, lânguida na tela impregnada de sua elegância " e "a perfeição do jovem perfil em luto de Hermínia, sua confidente". Essas expressões recategorizadoras evidenciam a axiologia na construção do referente, indicando o PDV do produtor do texto acerca da obra. Esse PDV orienta a construção do sentido por parte público ao mesmo tempo em que faz ver a maestria do artista. Essa axiologia, contudo, não se faz sem evocar valores morais, como evidenciam os termos enrugada, luto, sensualidade, lânguida e confidente, que colocam as personagens em posições distintas. Tais valores atestam a emotividade da cena representada na tela e confirmam a argumentação emocionada na plaqueta da figura 2.

$\mathrm{Na}$ segunda tela (figura 3 mais abaixo), cujo título é "Sofonisba", a personagem principal não aparece sensualizada como na anterior, o que confere tensão e seriedade ao momento. O título da tela evidencia nova introdução do referente, que aqui é construído a partir da relação com o veneno, elemento que causará sua morte. Ela segura a taça de forma hesitante e tem a cabeça e o olhar direcionados a um foco, não retratado no quadro, e que parece indicar apelo e receio ao que enfrentará. Os tons amarronzados da tela realçam a sobriedade do momento, ainda que a princesa permaneça iluminada. Na plaqueta, por sua vez, as expressões referenciais e argumentos utilizados coloquem em evidência a personagem e os pontos de vista que nela se constroem: 


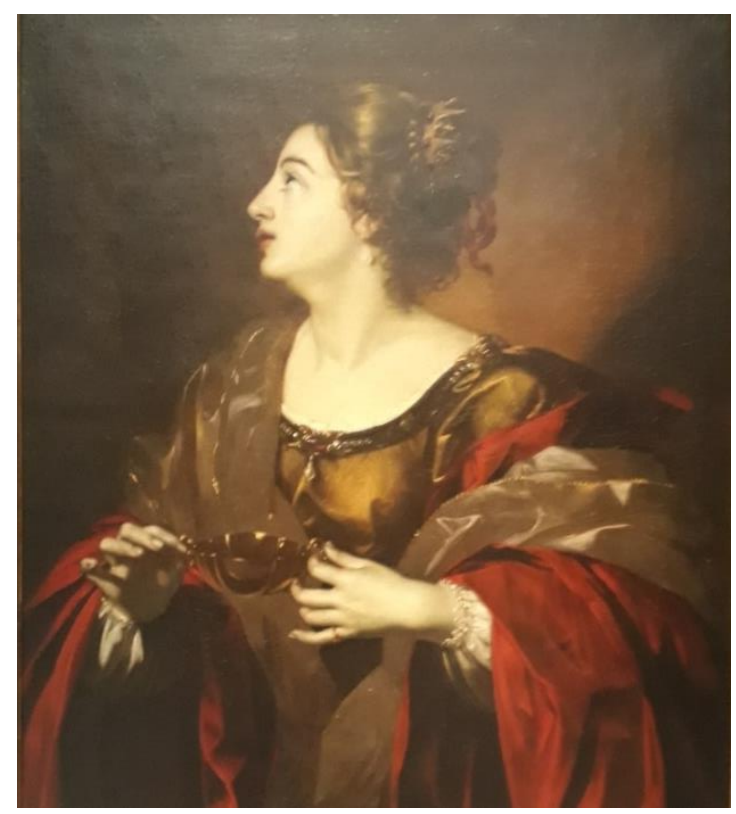

Figura 3: Detalhe da tela de Nicolas Régnier ${ }^{25}$ Sofonisba. 1650-1660. Padoue, Museo Civico.

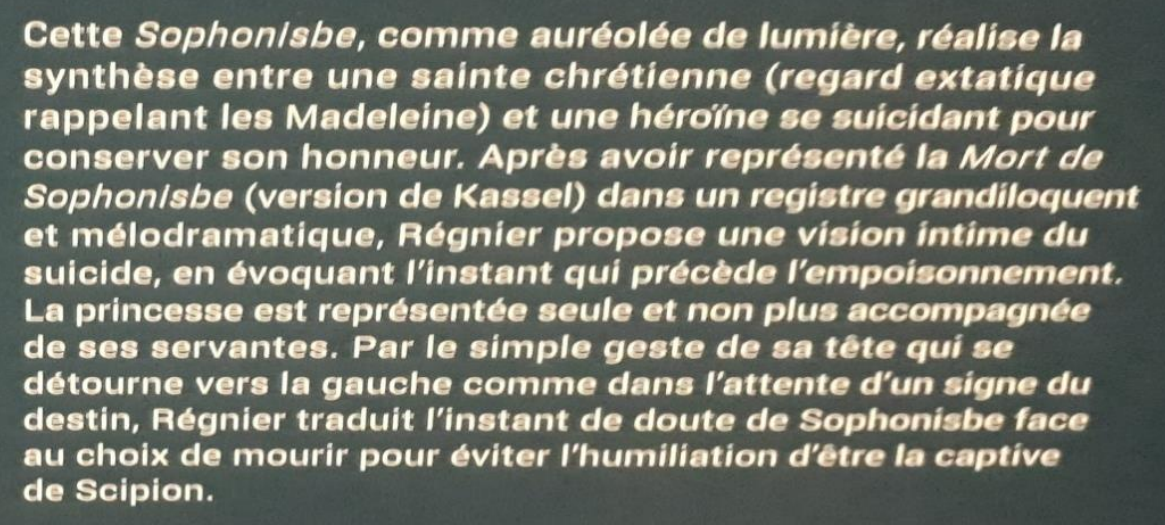

Figura 4: Plaqueta ${ }^{26}$ referente à tela "Sofonisba"

A plaqueta da figura 4 apresenta a personagem pelo dêitico "essa Sofonisba", apoiando-se no elemento não verbal para sua identificação e interpretação. Esse dêitico conjugado a outros elementos e saberes, eleva a personagem, deixando claramente explícito o ponto de vista do enunciador acerca da personagem, da obra e do fazer artístico do pintor que, segundo os curadores da exposição, "realiza" "a síntese entre uma santa cristã e uma heroína

\footnotetext{
${ }^{25}$ Idem nota 21.

${ }^{26}$ Texto da plaqueta da exposição L'Homme Libre, do Musée d'Artes de Nantes (França), referente à tela "Sofonisba" (figura 3). Tradução do trecho neste artigo: "Essa Sofonisba como auréola de luz, realiza a síntese entre uma santa cristã (olhar estático lembrando as Madalena) e uma heroína se suicidando para preservar sua honra. Depois de ter representado A Morte de Sofonisba (versão de Kassel) por um registro grandiloquente e melodramático, Régnier propõe uma visão íntima do suicídio, evocando o instante que antecede o envenenamento. A princesa é representada só e não mais acompanhada de suas criadas. Pelo simples gesto de sua cabeça que se inclina em direção à esquerda assim como à espera de um sinal do destino, Régnier traduz o instante de dúvida de Sofonisba face à escolha de morrer para evitar a humilhação de ser a prisioneira de Scipion."
} 
se suicidando para preservar sua honra". A comparação "como auréola de luz" reforça esse ponto de vista que põem em destaque personagem, autor e obra, juntamente com outros elementos que aí se identificam mobilizando o sensível. Por exemplo:

i) a expressão referencial "olhar estático lembrando as Madalena" conjuga o sentimento de piedade com conhecimentos acerca das Madalenas (em estado semelhante a Sfonista) pintadas pelo mesmo autor;

ii) as expressões "um registro grandiloquente e melodramático" e "uma visão íntima do suicídio" referem-se avaliativamente e de forma respectiva as telas 1 e 2 e utilizam-se de termos que apelam para o sensível, tais como "grandiloqente" e "suicídio". Concordamos com Amossy (2006, p.190) que "a emoção se inscreve em um saber de crença que desencadeia um certo tipo de reação face a uma representação social e moralmente impregnada. Das normas, valores, crenças implícitas subentendem as razões que suscitam o sentimento.";

iii) a expressão "a escolha de morrer" apela para o sensível pelo termo escolha, contribuindo para construir o PDV da personagem, ainda que ela não fale ou dê sua opinião. Constrói-se, emotivamente, a heroína (mesmo que suas emoções não sejam explicitadas) que aceita o presente do amado e morre por honra. Semelhantemente, a expressão "a humilhação de ser a prisioneira de Scipion" lança pelo termo humilhação o conteúdo perceptivo que expressa o PDV da personagem (ela se sente humilhada) e constrói emoção por inferência. Outra expressão atributiva que marca seu PDV é "a espera de um sinal do destino" (pobre Sofonisba, pois só um milagre poderia salvá-la).

Ao analisar que "Régnier traduz o instante de dúvida de Sofonisba face à escolha de morrer para evitar a humilhação de ser a prisioneira de Scipion", o enunciador manifesta seu ponto de vista sobre a tela, enquanto objeto de discurso, avaliando não apenas o que o pintor faz, ou seja, a sua linguagem estética, mas também atribuindo de forma empática e emotiva PDV a Sofonisba, que hesita ("instante de dúvida") perante à morte.

\section{Considerações finais}

Ao focalizar a axiologia dos processos referenciais no gênero plaqueta, este trabalho mostrou como a construção dos referentes é povoada de elementos (nos planos linguístico e cognitivo) que evocam o sensível a fim de representar emoções. Nessa dimensão, analisou alguns mecanismos de construção do PDV na argumentação emocionada: a heterogeneidade que a constitui pela atribuição e assunção de pontos de vista e o caráter dialógico da 
representação das emoções. Como estratégias argumentativas, no plano da evocação, as emoções aqui analisadas limitaram-se à produção do texto, procurando analisar em que medida elas podem guiar sua compreensão. Por isso, a preocupação com as emoções provocadas é um tema a ser ainda investigado, seja por meio de uma análise integradora da relação emoção-pathos, ou simplesmente do pathos, no plano da provocação ou dos sentimentos provocados (o que é diferente de orientar a compreensão analisando a evocação). Tal intento mostra a riqueza dos processos referenciais para o estudo da argumentação no campo da Linguística Textual em diálogo com estudos retórico-argumentativos e discursivos.

\section{REFERÊNCIAS}

AMOSSY, Ruth. L'Argumentation dans le discours. 2ed. Paris: Armand Colin, 2006. APOTHÉLOZ, Dénis; REICHLER-BÉGUELIN, Marie-José. Construction de la référence et stratégies de désignation. In: BERRENDONNER, A. e M-J REICHLER-BEGUELIN. (Eds). TRANEL, Neuchâtel, n.23, p. 227-271, 1995.

CAVALCANTE, Mônica Magalhães. Leitura, referenciação e coerência. In: ELIAS, Vanda Maria. Ensino de Língua Portuguesa: oralidade, escrita e leitura. São Paulo: Contexto, 2011. CAVALCANTE, Mônica Magalhães. Referenciação: uma entrevista com Mônica Magalhães Cavalcante. ReVEL, vol. 13, n. 25, p. 367-380, 2015.

CAVALCANTE, Mônica Magalhães. Abordagens da argumentação nos estudos de Linguística Textual. ReVEL, edição especial vol. 14, n. 12, p. 106-124, 2016.

CAVACANTE, M. M.; FILHO, V. C.; BRITO, M. A. G. P. Coerência, referenciação e ensino. São Paulo: Contexto, 2014.

CIULLA, Alena; MATOS, Janaica Gomes. Os processos de recategorização na construção avaliativo-argumentativa do texto. ReVEL, edição especial vol. 14, n. 12, p.258-277, 2016.

CUSTÓDIO FILHO, Valdinar. Reflexões sobre a recategorização referencial sem menção anafórica. Linguagem em (Dis)curso, Tubarão, SC, v. 12, n. 3, p. 839-858, set./dez. 2012. KOCH, Ingedore G.Villaça. Desvendando os segredos do texto. São Paulo: Cortez, 2002.

KOCH, Ingedore G.Villaça; MARCUSCHI, Luiz Antônio. Processos de referenciação na produção discursiva. Revista DELTA, São Paulo, n. especial, 14, 1998.

FORGET, Danielle. Le pathos mis à contribution dans les discours à grande circulation. Corela: cognition, représentation et langage, Poitiers, número especial 19, p.1-16, 2016.

MARCUSCHI, Luiz Antônio. O léxico: lista, rede ou cognição social. In: NEGRI, L; FOLTRAN, M. J.; OLIVEIRA, R. P. Sentido e significação em torno da obra de Rodolfo Ilari. São Paulo: Contexto, 2004.

MARCUSCHI, Luiz Antônio. A construção do mobiliário do mundo e da mente: linguagem, cultura e categorização. In: __ Cognição, linguagem e práticas interacionais. Rio de Janeiro: Lucerna, 2007. p.124-145.

MICHELI, Raphaël.; HEKMAT, Ida.; RABATEL, Alain. Les émotions: des modes de sémiotisation aux fonctions argumentatives. Semen, Besançon, v. 35, p. 7-16, abril 2013.

MONDADA, Lorenza; DUBOIS, Danielle. Construction des objets de discours et catégorisation: une approche des processus de référenciation. In: BERRENDONNER, Alain; Marie-Jose REICHLER-BEGUELIN. (Eds). TRANEL, Neuchâtel, n.23, p. 273-302, 1995. 
PINTO, R.; CORTEZ, S. L. Do pathos retórico à 'empatia rabateliana': argumentação emocionada em textos/discursos polêmicos. Revista de Letras, Fortaleza, v. 2, n. 36, p. 51-62, jul./dez 2017.

PLANTIN, Christian. A argumentação: história, teorias e perspectivas. São Paulo: Parábola, 2008.

RABATEL, Alain. Homo narrans. Pour une analyse énonciative et interactionnelle du récit. Tome 1. Les points de vue et la logique de la narration. Limoges : Editions Lambert-Lucas, 2008.

RABATEL, Alain. En amont d'une théorie argumentative de la polyphonie, une conception radicale de l'énonciation comme énonciation problématisante. Verbum: Revue de Linguistique, Nancy, v.38, n. 1-2, p. 131-150, 2016.

RABATEL, Alain. Pour une lecture linguistique des medias: empathie, étique et point(s) de vue. Limoges : Editions Lambert-Lucas, 2017.

Recebido em 31/03/2018. Aceito em 06/06/2018. 